\title{
APONTAMENTOS SOBRE POTENCIAIS RELAÇÕES ENTRE DESINFORMAÇÃO, COMPORTAMENTO E PRÁTICAS INFORMACIONAIS
}

\author{
Nicole Tirello Acquolini ${ }^{1}$ \\ Rodrigo Silva Caxias de Sousa ${ }^{2}$
}

\begin{abstract}
RESUMO
Ensaio que discute relações estabelecidas e potencialidades entre os conceitos de pós-verdade e desinformação no âmbito dos estudos de comportamentos e práticas informacionais que se efetivam na web, tendo como referência o paradigma social da Ciência da Informação. Assim, com o propósito de facilitar a compreensão e contribuir em relação à suplementaridade e convergência desses conceitos, quanto à abordagem de estudos de usuários, elencamos as distinções dos desdobramentos conceituais do termo desinformação e os tensionamentos potencializadores de estudos futuros. As reflexões permitem afirmar que a desinformação se consagra como cerne para a compreensão dos fenômenos informacionais no contexto do capitalismo cognitivo, através de comportamentos e práticas informacionais que instrumentalizam e deturpam os processos de comunicação até então consolidados.
\end{abstract}

Palavras-chave: desinformação; comportamento informacional; práticas informacionais; Ciência da Informação.

\begin{abstract}
This essay discusses established relations and potentialities between the concepts of post-truth and misinformation in the context of studies of informational behaviors and practices that take place on the web, having as reference the social paradigm of Information Science. Thus, with the purpose of facilitating the understanding and contributing in relation to the supplementarity and convergence of these concepts as approaches to user studies, we list the distinctions of the conceptual unfoldings of the term misinformation and the potential tensioning of future studies. The reflections allow us to affirm that misinformation is consecrated as the core for the understanding of informational phenomena in the context of cognitive capitalism, through informational behaviors and practices that instrumentalize and distort the communication processes consolidated until then.
\end{abstract}

Keywords: disinformation; informational behavior; informational practices; Information Science.

\section{INTRODUÇÃO}

A proposta ensaística que aqui se inicia busca suscitar aspectos relativos a potenciais embricamentos entre desinformação e os conceitos de comportamento e

1 Mestranda do Programa de Pós-Graduação em Ciência da Informação da Universidade Federal do Rio Grande do Sul (PPGCIN/UFRGS) e Bacharela em Biblioteconomia pela mesma Universidade. E-mail: nacquolini@gmail.com

2 Doutor em Comunicação e Informação pela Universidade Federal do Rio Grande do Sul. Professor permanente do Programa de Pós-Graduação em Ciência da Informação (PPGCIN/UFRGS). Professor adjunto III do Departamento de Ciência da Informação da Universidade Federal do Rio Grande do Sul (UFRGS). E-mail: rodrigo.caxias@ufrgs.br 
práticas informacionais. Em virtude da livre composição e estrutura do ensaio, que pode se constituir em "[...] uma exegese que pretende, para além da interpretação, colocar luzes sobre alguns pontos ou aspectos que podem ser propícios para a discussão." (MEDEIROS, 2020, p. 202), buscamos atentar para a importância, os desdobramentos e as potencialidades investigativas que o termo desinformação passou a engendrar no âmbito da Ciência da Informação $(\mathrm{Cl})$, especialmente no que se refere aos estudos de usuários.

Isso porque o modo de produção no capitalismo cognitivo fundamenta comportamentos sociais no âmbito do self, bem como configuram práticas sociais coletivas balizadas, concomitantemente, tanto em informações verídicas quanto falsas. Dessa forma, informar não deve se dicotomizar diante do ato de desinformar. A limítrofe fronteira entre essas informações, produto de comportamentos e práticas instantâneas, acaba por se esvair tendo por referência a mesma velocidade com que as informações são produzidas. Essa efemeridade e volatilidade das informações e desinformações (consideradas também suas variações terminológicas) referem-se a um movimento de disseminação de conhecimentos aplicados a uma estrutura política que se fundamenta em um imaginário de crise dos fundamentos da verdade.

Materializada muitas vezes no âmbito digital, esse tipo de ação, que tem por alicerce distintos comportamentos e práticas informacionais, acaba tornando-se manifestação da violação de direitos fundamentais, resultando em intervenção de cunho político, econômico e ideológico, comprometendo o caráter libertário característico da livre e indiscriminada socialização de informações fundamentadas na verdade. Trata-se de perigoso artifício que compromete o viés progressista e libertador do desenvolvimento social e das democracias (SAMPAIO; LIMA; OLIVEIRA, 2018).

Portanto, a necessidade de problematizar a questão da desinformação, assunto amplamente presente e significativo em uma sociedade de controle (DELEUZE, 2013) e tendo por finalidade a proposição de encontrar meios para entendê-lo, combatê-lo e conjugá-lo na dimensão dos estudos de comportamento e práticas informacionais, efetivamos uma breve reflexão sobre o paradigma social da Ciência da Informação, a respeito da correlação entre os conceitos de pós-verdade, desinformação, comportamento e práticas informacionais na web. 
2 PARADIGMA SOCIAL ÀS APROXIMAÇÕES CONCEITUAIS: potencialidades investigativas

A assimilação da desinformação como um fenômeno social requer uma menção à compreensão dos distintos paradigmas que se constituem como referência aos estudos na área da Ciência da Informação.

Em seu estudo a respeito dos paradigmas da Ciência da Informação, Capurro (2003) elucida que a $\mathrm{Cl}$ surgiu em meio ao século XX com um paradigma físico (informação vista como um objeto da realidade cujo significado independe do usuário que se relaciona com ela). A outra perspectiva adotada está relacionada ao paradigma cognitivo (informação compreendida como um elemento de atribuição de sentido dado por um sujeito perante seu estado anômalo de conhecimento). E a terceira, o paradigma social (referente à natureza social e coletiva do uso da informação) considera as implicações da produção, circulação, compartilhamento, uso e troca de informações, interpretando a informação como um fenômeno condicionado pelo contexto, historicidade e intervenções de cunho tecnológico, político e social.

Nessa vertente intelectiva ao considerarmos as distinções sumariamente elencadas, é possível ponderar que quando compreendidos de forma integrada e não linear, suas interpretações tornam-se bastante coerentes. Decorrente de tal proposição, neste ensaio, os conceitos são apresentados de maneira fundamentada no paradigma social (discutido também por outros autores além de Capurro (2003), como: Rendón Rojas (2005) e Hjørland (2002), pois interpretamos ser esse o viés paradigmático mais adequado para a apreensão dos fenômenos de desinformação, assim como também o que mais proporciona elementos pertinentes para ampliações no subcampo de estudos de usuários, subárea da $\mathrm{Cl}$ em que a presente temática se insere.

Ao sustentar que o paradigma social desponta como condutivo às discussões relativas a perspectivas de como os fluxos informacionais e suas demandas se dão através das construções, conjunturas e correlações sociais, defendemos que as acepções devam estar concentradas em condicionantes políticos, históricos, tecnológicos, culturais e econômicos (como já mencionado anteriormente). A possibilidade de investigarmos de maneira exaustiva aspectos do processo social de produção de desinformações, a luz de comportamentos e práticas informacionais, 
está a desvelar as projeções de poder que se edificam por intermédio da proliferação de mentiras e informações falsas, em última instância, relações de controle articuladas entre o capital privado, o governo e a sociedade civil.

Essas "redes nefastas de desinformação" expõem o contexto no qual os sujeitos informacionais estão inseridos e as repercussões da socialização de informações no âmbito das coletividades. Ademais, permitem que interpretações de fenômenos sociais, conduzam e proporcionem ampliações epistemológicas a Ciência da Informação, projetando-a para um prisma centrado no significado da informação e nas relações entre os discursos. Deste modo, os problemas explanados sob o enfoque da informação carecem ser concebidos perante os assujeitamentos individuais e coletivos que incidem sobre a estrutura social e as relações dela provenientes. Ou seja, tem-se o potencial de depreender a informação configurada a um fenômeno da ordem cultural e da humanidade (NASCIMENTO; MARTELETO, 2004). Isto posto, pode ser latente o seguinte efeito:

[...] abandonar a busca de uma linguagem ideal para representar 0 conhecimento ou de um algoritmo ideal para modelar a recuperação da informação, como aspiram os paradigmas 'físico e o cognitivo', pois considera as possíveis perspectivas ou pontos de acessos distintos de acordo com o interesse do usuário ou comunidade. (CAPURRO, 2003, p. 9).

Logo, é essencial atentarmo-nos aos distintos pontos de acesso conforme as aspirações do usuário e/ou das relações e implicações advindas das necessidades, demandas, produção, compartilhamento, troca, uso, reuso e consumo de informações e desinformações socializadas entre a comunidade. Nesse sentido, estudos de comportamento e práticas informacionais se mostram frutíferos como forma de evidenciar fenômenos relativos ao binômio informação-desinformação, apoiados na abordagem alternativa e na abordagem alternativo-crítica. Capurro (2003) descreve também uma potencial junção entre o paradigma cognitivo (individualista) e o paradigma social, em que diferentes indivíduos vinculados a uma comunidade legitimam seus parâmetros de seleção e significados informacionais.

Além disso, é importante observar que devido à sobreposição com estudos de outras áreas, a $\mathrm{Cl}$, proveniente das ciências sociais aplicadas, faz-se também inter/transdisciplinar, possibilitando diversas trocas e construções teóricas pertinentes para este estudo. 


\subsection{Comportamento e práticas informacionais}

No âmbito do campo de estudo de usuários, na década de 90, outro enfoque foi se desenvolvendo: os estudos de práticas informacionais, ou seja, "[...] o estudo do movimento por meio do qual os indivíduos agem no mundo, conformados pela cultura, e ao mesmo tempo constituem essa cultura que os influencia e a realidade em que atuam." (ARAÚJO, 2017, p. 21).

No começo, essa abordagem concentrava-se em estudos de usuários na vida cotidiana, ao contrário da vertente tradicional que se direcionava a esfera empresarial, científica e governamental. Subsequentemente, sua constituição transformou-se numa perspectiva que abarcava todas as categorias de vivência empírica. No qual, uma importante contribuição dessa vertente é a concepção de que não existe uma realidade externa independente dos indivíduos e seus atos, pois são os indivíduos, a partir de seus atos que geram e renovam as regras e normas sociais. Ademais, diferentemente da proposta do comportamento informacional (abordado a seguir), estes estudos progrediram no entendimento da informação não como um processo vivenciado exclusivamente na perspectiva individual cognitiva, mas sim a partir de uma perspectiva informacional que englobe também processos de apropriação, imaginação e questionamentos concebidos a partir da construção social (ARAÚJO, 2017).

Isto é, conforme estes preceitos, podemos entender que a manutenção do status quo que abriga as práticas informacionais, se dá através dos sujeitos e suas ações dentro de uma comunidade ou meio social, indo assim ao encontro da perspectiva social mencionada anteriormente. Desta maneira, podemos refletir também num indivíduo do "conhecimento", a partir de suas práticas sociais, "[...] entendido como aquele que interage com outros sujeitos na construção da informação." (FREIRE; AQUINO, 2000, p. 76). Este indivíduo do "conhecimento" é encarregado da recepção, transmissão, usabilidade, comunicação, geração, acessibilidade e socialização da informação. Enfim, todo o processo de cidadania que pode se fazer através do uso e acesso à informação (ARAÚJO, 2001).

Já o comportamento informacional, tem a seguinte definição: todo comportamento humano direcionado às fontes e canais de informação, abrangendo a busca ativa (information seeking behavior) conforme alguma necessidade e a busca e recepção passiva da informação, assim como o seu uso (information use 
behavior) relacionado às ações cognitivas consoantes aos conhecimentos prévios do sujeito. Podendo incluir também a comunicação pessoal e presencial da informação (WILSON, 2000).

Esta formulação pode ser utilizada também para caracterizar as distintas formas pelas quais os sujeitos interagem com a informação, incluindo a maneira como as pessoas usam e buscam a informação. Assim, os comportamentos de seleção, uso e busca da informação, auxiliam na compreensão de como as informações podem ser consumidas e explicar a suscetibilidade dos sujeitos às desinformações (tema abordado a seguir) (CORRÊA; CAREGNATO, 2021).

Considerando essa diversidade conceitual, no âmbito da web, percebem-se impasses que demandam alterações tecnológicas condicionantes na maneira como os usuários se relacionam com as informações e produtos disponibilizados na rede. Tais variações possibilitam que um fluxo de adversidades sociais abordados em diferentes contextos se consolide em latentes práticas e comportamentos informacionais a serem investigados. Essas práticas revelam variantes em relação a públicos específicos, e apontam o quanto a rede pode se constituir também num foco de investigação para distintas áreas do conhecimento, caracterizando-se em um ambiente de manifestação de poder em que reafirma as relações de desigualdades estabelecidas pela lógica do capitalismo (SOUSA et al., 2019).

\subsection{Desinformação e variações}

$\mathrm{Na}$ atualidade, a informação com seu caráter instantâneo, efêmero e interativo subsidia a ampliação de possibilidades investigativas ao paradigma social da $\mathrm{Cl}$, em virtude aos indivíduos encontrar-se submersos em espaços 'sócio tecnológicos' com variadas linguagens e rápida disseminação de desinformações, seguindo a lógica de produção e falta de validação de informações. Para Sousa et al. (2021, p. 177):

Ao depararmo-nos com a danificação e ruptura das formas de produção simbólica de informações, buscamos compreender que o uso indiscriminado de (des)informação com o propósito de manipular e distorcer a opinião pública, torna-se estratégia preponderante. Como consequência, entram em risco a democracia, as mais honestas práticas informacionais e amplia-se o abismo informacional.

Então, a percepção do paradigma social necessita conviver também com os novos instrumentos tecnológicos, a partir da explosão informacional e das mídias sociais. Deste modo, não se tem apenas o lado positivo (como o de aprendizagem, 
por exemplo), mas também o negativo, no qual, provoca ruídos e prejuízos sociais de toda ordem, sendo nesse âmbito que se destaca a desinformação e a pósverdade:

A pós-verdade reside precisamente em descaracterizar a relação entre o verdadeiro e o falso e desfigurar uma relação entre o nãosenso de sentido (elementos de intervenção/ interferência subjetiva e recepção) e o não-senso de significado (representação mental significa) que se firmam na relação de exclusão entre o que seria verdadeiro ou falso, conforme as evidências ideológicas e convicções psíquicas. (SILVA, 2018, p. 4).

E segundo o Grupo de Pesquisa em Comportamento e Competências Infocomunicacionais (2020, p. 16) através do Glossário de Conceitos Infocomunicacionais, pós-verdade diz respeito à "[...] circunstância em que se dá maior valor à opinião pública, às emoções, à crença pessoal do que para a verdade e para os fatos. Terreno fértil para a proliferação de desinformação.”.

Portanto, para caracterizar o ato de desinformar (paralelamente a pósverdade), se faz necessário trazer um conceito bastante completo:

Desinformação envolve informação descontextualizada,
fragmentada, manipulada, retirada de sua historicidade, tendenciosa,
que apaga a realidade, distorce, subtrai, rotula ou confunde. A
desinformação neste sentido não é necessariamente falsa; muitas
vezes, trata-se de distorções ou partes da verdade. (BRISOLA;
BEZERRA, 2018, p. 3319).

Em inglês, há dois termos empregados para corresponder à desinformação, sendo eles: misinformation e disinformation. Ambos significam informações falsas, entretanto, misinformation pode ser entendida como falsidade contingente e disinformation pode ser assimilada a falsidade intencional (STAHL, 2006).

Karlova e Fisher (2013) entendem misinforming e disinforming como maneiras de comportamento informacional, em que necessitam ser investigadas no contexto da competência informacional. Compreendem também misinformation como informação imprecisa e disinformation como informação enganosa, sendo as duas apontadas como subcategorias de informação e podendo conter algum tipo de informatividade, mesmo que de maneira involuntária.

Devido tais constatações, entendemos o quanto é necessário que a sociedade saiba filtrar e apurar a veracidade das fontes, para que se possa fazer bom uso de toda informação. De acordo com Zattar (2017) ter acesso às fontes de informações é uma responsabilidade diária e fundamental na atualidade. Porém, não 
é suficiente que se tenha alcance a qualquer tipo de informação, é preciso também qualidade, relevância e veracidade, de forma que sejam evitadas desinformações e notícias falsas nas bolhas informacionais das quais fazemos parte.

O requisito de práticas informacionais éticas e críticas atestam a importância de verificação das fontes de informação usadas no cotidiano, sendo fundamental a avaliação do que é informação ou desinformação em determinado contexto, principalmente nas redes sociais.

\section{CONSIDERAÇÕES FINAIS}

O propósito deste trabalho foi de problematizar questões relativas à aproximação acerca dos conceitos de desinformação, práticas e comportamento informacionais, tendo como referência o paradigma social da Ciência da Informação e contribuir para demais trabalhos da área, possibilitando um melhor entendimento sobre o assunto.

Em vista das redes sociais terem se tornado um espaço favorável para os fenômenos da pós-verdade e da disseminação de desinformações, um letramento informacional digital dos usuários conectados se faz muito importante. Para que isso aconteça, é fundamental que o corpo social possa depreender de meios para uma efetiva verificação da credibilidade das fontes, assim como a autenticidade dos dados compartilhados. Portanto, é de suma importância impedir a banalização da pós-verdade e a recepção natural de notícias falsas e desinformações, apenas porque ressaltam opiniões e crenças particulares.

Para combater esse preocupante problema, a sociedade precisa estar consciente de que a mudança se dará através de uma reforçada educativa, com um viés progressista e libertador, contrariando a lógica capitalista e mercantilista que nos permeia. Por isso, aqui neste ensaio, as possibilidades de estudos centrados no comportamento e práticas informacionais de desvelamento aos fenômenos de desinformação, devem ser percebidos como atos de resistência dos indivíduos e das coletividades, ampliando possibilidades de compreensão de ações informacionais que acontecem no mundo contemporâneo e sejam interpretadas por investigadores da Ciência da Informação.

\section{REFERÊNCIAS}

ARAÚJO, E. A. Informação, sociedade e cidadania: práticas informacionais de organizações não governamentais (ONGs) brasileiras. Informação e Informação, 
Londrina, v. 6, n. 1, p. 31-54, 2001. Disponível em:

http://www.uel.br/revistas/uel/index.php/informacao/article/view/1683. Acesso em: 13 maio 2021.

ARAÚJO, C. A. V. Uma história intelectual da ciência da informação em três tempos.

RACIn - Revista Analisando em Ciência da Informação, [s. I.], v. 5, n. 2, p. 10-29, jul./dez. 2017. Disponível em: http://hdl.handle.net/20.500.11959/brapci/80719.

Acesso em: 13 maio 2021.

BRISOLA, A.; BEZERRA, A. C. Desinformação e circulação de "fake news": distinções, diagnóstico e reação. In: ENCONTRO NACIONAL DE PESQUISA EM CIÊNCIA DA INFORMAÇÃO, 19., 2018, Londrina. Anais eletrônicos [...]. Londrina: ANCIB, 2018. Disponível em: http://hdl.handle.net/20.500.11959/brapci/102819. Acesso em: 13 maio 2021.

CAPURRO, R. Epistemologia e ciência da informação. In: ENCONTRO NACIONAL DE PESQUISA EM CIÊNCIA DA INFORMAÇÃO, 5., 2003, Belo Horizonte. Anais eletrônicos [...]. Belo Horizonte: Associação Nacional de Pesquisa e PósGraduação em Ciência da Informação, 2003. Disponível em:

http://www.capurro.de/enancib_p.htm. Acesso em: 13 maio 2021.

CORRÊA, M. V.; CAREGNATO, S. E. Desinformação e comportamento informacional nas mídias sociais: a divulgação científica na prevenção ao novo coronavírus. Informação \& Informação, Londrina, v. 26, n. 1, p. 161-185, 2021. Disponível em:

http://www.uel.br/revistas/uel/index.php/informacao/article/view/41428. Acesso em: 13 maio 2021.

DELEUZE, G. Post-scriptum sobre as sociedades de controle. In: DELEUZE, G. Conversações. 3. ed. São Paulo: Ed.34, 2013.

FREIRE, B. M. J.; AQUINO, M. A. Ciência da Informação: buscando abrigo para um sujeito. Transinformação, Campinas, v. 12, n. 2, p. 71-79, 2000. Disponível em: http://periodicos.puc-campinas.edu.br/seer/index.php/transinfo/article/view/ 1529/1503. Acesso em: 12 nov. 2019.

HJØRLAND, B. Epistemology and the sócio-cognitive perspective in Information Science. Journal of the American Society for Information Science and Technology, New York, v. 53, n. 4, p. 257-270, 2002. Disponível em: https://onlinelibrary.wiley.com/doi/abs/10.1002/asi.10042. Acesso em: 13 maio 2021.

GRUPO DE PESQUISA EM COMPORTAMENTO E COMPETÊNCIAS INFOCOMUNICACIONAIS (org.). Glossário de conceitos infocomunicacionais. Porto Alegre: InfoCom, 2020. Disponível em: https://www.ufrgs.br/infocom/wpcontent/uploads/2020/11/Glossario-Final-Revisado.pdf. Acesso em: 15 jan. 2021.

KARLOVA, N. A.; FISHER, K. E. A social diffusion model of misinformation and disinformation for understanding human information behaviour. Information Research, [s. I.], v. 18, n. 1, 2013. Disponível em: http://informationr.net/ir/18-1/paper573.html\#.Ybo0pb3MKyl. Acesso em: 13 maio 2021.

MEDEIROS, J. da S. Algoritmos como dispositivos produtores de subjetividades: um ensaio de compreensão em Michel Foucault e Gilles Deleuze. Informação em 
Pauta, Fortaleza, v. 5, n. 2, p. 201-211, 2020. Disponível em:

http://www.periodicos.ufc.br/informacaoempauta/article/view/60269. Acesso em: 13 maio 2021.

NASCIMENTO, D. M.; MARTELETO, R. M. A informação construída nos meandros dos conceitos da teoria social de Pierre Bordieu. DataGramaZero: Revista de Ciência da Informação, [s. I.], v. 5, n. 5, 2004. Disponível em: http://hdl.handle.net/20.500.11959/brapci/5679. Acesso em: 13 maio 2021.

RENDÓN ROJAS, M. Á. Relación entre los conceptos: información, conocimiento y valor. Semejanzas y diferencias. Ciência da Informação, Brasília, DF, v. 34, n. 2, p. 52-61, maio/ago. 2005. Disponível em: http://revista.ibict.br/ciinf/article/view/1090. Acesso em: 13 maio 2021.

SAMPAIO, D. B.; LIMA, I. F.; OLIVEIRA, H. P. C. Estratégias fact-checking no combate à fake news: análises informacional e tecnológica no e-farsas e boatos.org. In: ENCONTRO NACIONAL DE PESQUISA EM CIÊNCIA DA INFORMAÇÃO, 19., 2018, Londrina. Anais eletrônicos [...]. Londrina: ANCIB, 2018. Disponível em: http://hdl.handle.net/20.500.11959/brapci/103103. Acesso em: 13 maio 2021.

SILVA, J. L. C. Pós-verdade e informação: múltiplas concepções e configurações. In: ENCONTRO NACIONAL DE PESQUISA EM CIÊNCIA DA INFORMAÇÃO, 19., 2018, Londrina. Anais eletrônicos [...]. Londrina: ANCIB, 2018. Disponível em: http://hdl.handle.net/20.500.11959/brapci/103784. Acesso em: 13 maio 2021.

SOUSA, R. S. C. de et al. Em busca de categorias de mansplaining: pesquisadoras compartilhando informações sobre violências sofridas. Liinc em Revista, [s. I.], v. 15, n. 1, 2019. Disponível em: http://revista.ibict.br/liinc/article/view/4603. Acesso em: 13 maio 2021.

SOUSA, R. S. C. de et al. Fetichismo da desinformação na web: uma pandemia agravada. Revista TOMO, [s. I.], n. 38, 2021. Disponível em:

https://seer.ufs.br/index.php/tomo/article/view/14452. Acesso em: 13 maio 2021.

STAHL, B. C. On the difference or equality of information, misinformation, and disinformation: a critical research perspective. Informing Science, [s. I.], v. 9, p. 8396, 2006. Disponível em: https://www.informingscience.org/Publications/473. Acesso em: 13 maio 2021.

ZATTAR, M. Competência em informação e desinformação: critérios de avaliação do conteúdo das fontes de informação. Liinc em Revista, Rio de Janeiro, v. 13, n. 2, p. 285-293, nov. 2017. Disponível em: http://revista.ibict.br/liinc/article/view/4075.

Acesso em: 13 maio 2021.

WILSON, T. D. Human information behavior. Informing Science, [s. I.], v. 3, n. 2, p. 49-56, 2000. Disponível em: http://inform.nu/Articles/Vol3/v3n2p49-56.pdf. Acesso em: 13 maio 2021. 